\title{
Orthodontic Status and Head Morphology in Young Males
}

\author{
Nadezda V. Lupacheva \\ Institute and Museum of Anthropology, Moscow State University, Moscow, Russian Federation
}

\begin{abstract}
Complete anthropometrical data on a sample of 111 Russian males aged 20.0 2.3 years were obtained to investigate craniofacial morphology according to individual orthodontic status (OS). Subsample analyses were performed, using a variety of grouping factors. a) 1-spacing on both dental arches; 2-absence of crowding, spacing, rotation, or displacement of teeth on both dental arches; 3-crowding on both dental arches; b) 1-spacing on mandible; 2-absence of crowding, spacing, rotation, or displacement of teeth on mandible; 3-crowding on mandible; c) 1-spacing on maxilla; 2-absence of crowding, spacing, rotation, or displacement of teeth on maxilla; 3-crowding on maxilla. Wilks' Lambdas were found to be 0.29 to 0.59 ; all were significant.

Conclusions:
\end{abstract}

1. Significant positive and negative correlations were found between craniofacial measurements and an individual's OS.

2. Measurements exhibited statistically significant differences between the groups with different OS at the $p<0.05$ level and some at $p<0.01$.

3. Using forward stepwise discriminant analysis, a high difference in craniofacial architecture between the groups with different OS was found. Canonical discriminant analysis indicates the face pattern connected to crowding: relatively high medial vertical mandible height in combination with a vertically long and narrow face; to spacing: a wide face with wide nose and high upper lip is combined with shortened medial vertical mandible height.

4. Depending upon the grouping factor, 10 to 12 variables were chosen in the canonical discriminant model. Classification functions and means of canonical roots were calculated; morphological interpretations of canonical roots were performed.

5. Definitive OS is a complicated product of interaction during the ontogenesis of jaws between the time of teeth eruption and the growth of two growth fields (alveolar and corpus) under the simultaneous influence of hormonal status and the chronological age of the individual. $J$ Physiol Anthropol 26(3): 387-402, 2007 http://www. jstage.jst.go.jp/browse/jpa2

[DOI: $10.2114 / \mathrm{jpa} 2.26 .387]$
Keywords: orthodontic status, crowding, spacing, craniofacial patterns, facial growth, DMFT index, head morphology

\section{Introduction}

The origins of malocclusions during latter stages of human evolution have been discussed elsewhere. In general, three theories have been developed to explain the high prevalence of dental crowding in modern cosmopolitan populations. One theory is that an evolutionary trend towards diminution of growth in the facial skeleton has occurred without a corresponding change in tooth dimensions (Hooton, 1947). Recently Moore et al. (1968) compared dimensions of teeth and mandible measurements from Neolithic to modern times and offered support for Hooton's model. Alternatively, Brash (1956) suggested that dental irregularities in modern cosmopolitan populations is high in comparison to a modern but traditional-living (aboriginal) population because the diet is composed of less fibrous and tough-to-chew foods. This produces a diminution of the mechanical stimuli for growth of the facial skeleton. Brader (1972) concluded that primary determinants of arch form morphology are the muscle forces in resting and functioning states. It has been shown experimentally by Weijs and Hillent (1986) that a decrease in jaw muscle size in various animals has a similar effect on facial width and mandibular length. Their results support the hypothesis that in humans the jaw muscles affect facial growth and partly determine final facial dimensions. They also hint that the role of each muscle on facial growth is different. Although habitual activity of the masseter muscle in natural environments is not influenced by the vertical craniofacial morphology (Farella et al., 2005), we cannot be sure from this study that people with different types of vertical morphology have the same rate of masticatory activity.

Another theory discussed by Brash (1956) suggests that present-day populations represent an intermingling of peoples from diverse and physically dissimilar stocks. Interbreeding leads to skeletal disharmonies. Furthermore, Lundström (1951) presented evidence for independent genetic controls of teeth relative to jaws. Thus, it is possible that such a mechanism 
might result in discrepancies between the size of jaw and dentition.

A study comparing the crowding index from an historic population of the 19th century and a modern population showed a significant difference, with greater crowding in the modern population $(p<0.05)$ (Vyslozil and Jonke, 1994, cited by Moskers et al., 2004). The ancient population of Roaix differs considerably from these data, crowding being clearly greater in this prehistoric population than in the population of the 11th century and in modern populations (Moskers et al., 2004). Furthermore, all adults of this prehistoric population showed dental crowding, while crowding in the modem population has been reported to be $70-80 \%$ (Sinclair and Little, 1983; Proffit et al., 1998) These findings are in contrast to the results of Andrik (1963, cited in Moskers et al., 2004), who reported that malocclusions were rare in prehistoric populations and noted a crowding prevalence of only 1 percent from the Bronze Age; and Mirgazizov et al. (1998) who showed that during the last three thousand years dental arch structural anomalies increased to tenfold. Thus, crowding may be of genetic origin and might not be caused by excessive tooth size or changes in environmental factors (masticatory activity), at least in isolated populations (Moskers et al., 2004).

Crowding is one of the most frequent types of malocclusion in children and also the chief complaint of many parents referred to orthodontic departments. In Russia, it often remains untreated in adults-so the need for orthodontic treatment is high. Crowding and spacing are identified as a discrepancy between the mesiodistal tooth widths of the four permanent incisors and the available space in the alveolar process. A review of the literature indicated conflicting results regarding factors contributing to crowding and spacing.

Schwarz (1960) concluded from his cephalometric and gnathometric analysis that every malocclusion can be combined with all natural variations of skull morphologies and there is no connection between the two (cited after Siriwat and Jarabak 1985). Shudy (1965) found no correlation between morphologic pattern and specific types of occlusion in 270 subjects. But he found that in 400 malocclusions the occlusion/mandibular plane angle and Sella-Nasion/mandubular angle were excellent indicators of facial type. Howe et al. (1983) and Sinclair and Little (1983) also found no clinically significant associations between various mandibular parameters and incisor crowding. Miethke and Behm-Menthel (1988) reported that cephalometric measurements of patients with and without crowding did not differ significantly. They did not find any correlation between mandibular anterior crowding and vertical craniofacial configuration and sagittal lower incisor inclination. In view of their results, they suggest lower incisor crowding is a "local, independent, genetically determined discrepancy between tooth width and size of supporting bone."

Sakuda et al. (1976) reported a significant correlation between an increase in lower incisor crowding and high mandibular plane angles, short mandibular body lengths, greater upper face height, and small vertical dimensions in the upper posterior segments. Leighton and Hunter (1982) compared the skeletal morphology of cases with spacing, with moderate crowding and severe crowding of lower incisors. They reported shorter posterior facial heights and mandibular bodies for cases with crowding; mandibular prognathism increased more in the spaced cases.

Determination of factors contributing to anterior spacing or crowding, especially in the early mixed dentition stage and predicting permanent incisor crowding at an early stage are of great importance for orthodontic treatment planning. Towards this aim, several longitudinal studies evaluating mandibular dental crowding were performed during the primary, mixed, and permanent dentition stages. (Sanin and Savara, 1973; Howe at al., 1983; Hunter and Smith, 1972; Doris et al., 1983; Leighton and Hunter, 1982; Sampson and Richards, 1985; Berg, 1986; Bishara et al., 1986, 1995, 1998a, 1998b; Melo et al., 2001). Melo et al. (2001) evaluated indicators of crowding found in primary dentition, which could lead to future mandibular anterior crowding in the mixed dentition stage. They found that crowding is often related to arch dimensions. Few studies have evaluated the relationship between crowding and cephalometric measurements made on cephalograms and we were not able to access studies based on anthropometric measurements of any human population. Previous research into the origins of lower incisor crowding has not yet established the part played by skeletal morphology in its development. Berg (1986) compared cephalometric variables of patients with and without crowding and found that variables related to lower jaw dimensions had significantly smaller values in the crowded group. Several other reports have also indicated that crowding occurred more frequently in less prognathic cases (Ronnerman and Thilander, 1988; Leighton and Hunter, 1982; Lundstrüm, 1975)

Although crowding is considered as the most prevalent form of malocclusion (Helm, 1970; Tang, 1994; Proffit et al., 1998; Otuyemi et al., 1999; Thilander et al., 2001), a period of slightly crowded mandibular incisors is accepted as part of normal development. Sanin and Savara (1973) evaluated 150 children and reported that $89 \%$ of those with crowding in early mixed dentition also had crowding in permanent dentition, with only $11 \%$ showing complete correction. Except for two cases, the other self-correcting cases had no more than $0.5 \mathrm{~mm}$ crowding in the early mixed dentition. Tanabe et al. (2002) show that at ages 3,4 , and 5 years old the mean profiles of children remain similar in shape although the size of each profile enlarged with age. Sagittal skeletal relationships remained constant from early to late mixed dentition (mean age $9.31 \pm 1.52$ years). No significant differences were found between the observed developmental stages. Bishara and Jakobsen (1985) demonstrated that $77 \%$ of people maintained their facial types from 5 to 25.5 years of age. Other longitudinal studies comparing growth of open-bite and deep-bite subjects have demonstrated that, although there are differences in the magnitude and direction of growth changes, they follow 
similar patterns (Bishara and Jakobsen, 1985; Nanda, 1988, 1990; Karlsen, 1995). Longitudinal craniofacial growth curves based on multilevel procedures can accurately describe population and individual growth curves, and 5-year predictions with this method are highly accurate and externally valid. Correlations between predicted and actual values ranged from 0.81 to 0.96 , explaining the $66 \%$ to $92 \%$ of variation (Chvatal et al., 2005).

Cherdantsev (2003) stated that there are two ways to investigate morphogenetic variance: longitudinal observation of individual ontogenetic processes or comparison of the same age individuals. The second way is more convenient because the sample is easier to collect and the sample size is limited only by the investigator's patience. That is why we assume that studying a trait in its definitive state may shed light on mechanisms of its formation during ontogenesis. Thus, we suppose that if some morphological patterns in head and face architecture do exist at the mature stage, there were indications of this pattern during the growth period. Also, selection of discriminating traits is easier when morphology of the region of interest (craniofacial in our case) is already formed. Then we can choose meaningful variables for future study to follow during development, armed with the knowledge of head and face architecture that related to precise final orthodontic status, such as crowding, spacing, or harmonious development. Gathering data on adults also is much easier regarding time consumption because smaller sample sizes and fewer repeated observations are needed. Furthermore, it is easier regarding ethical considerations since adults can decide for themselves whether to participate in a study or not and there is less need for explanation.

Incisor crowding is not merely a tooth-arch size discrepancy, but a discrepancy among many variables (Sanin and Savara, 1973). Several factors can be assumed to affect the development and severity of crowding, such as direction of mandibular growth (Bjork, 1963; Perera, 1987), early loss of deciduous molars (Ronnerman and Thilander, 1978), mesiodistal tooth and arch dimensions (Howe et al., 1983), the oral and perioral musculature and incisor and molar inclination (Sanin and Savara, 1973), and human growth hormone (Sarnat et al., 1988; Kjellberg et al., 2000). Opinions about relations between the human growth hormone $(\mathrm{GH})$ and severity of dental crowding were tested on patients with dwarfism. Kjellberg et al. (2000) stated that short-statured boys might be in greater need of orthodontic treatment due to their higher percentage of dental crowding. The main findings of Sarnat et al. (1988) were that human GH therapy did not accelerate dental age but enhanced bone age; the mandible was significantly smaller in the untreated group but no significant difference was found between the groups in the maxilla; and crowding was less prevalent than expected and the mesiodistal width of the teeth seemed to be smaller. No articles with notes about crowding in acromegaly patients were available.

It has been argued that growth of the face is modular and is governed by growth of multiple contiguous soft tissues and functioning spaces (functional matrices). Brader (1972) considers that the dental arch form of an individual is a predictable module of a lager morphogenetic pattern-a harmonious part of the total craniofacial architecture. The particular architecture can be affected by mechanical and nervous stimulation along with the inherited potential to grow. Despite the trigeminal nerve exerting a trophic influence on the craniofacial complex; the conclusion that trophic effects constitute a major factor in the regulation of craniofacial growth cannot be supported (Behrents and Johnston, 1984).

The aims of this study were: 1 . To examine associations between facial morphology and malocclusions; 2. To determine the possible indicators of crowding and spacing in the permanent dentition from anthropometric measurements; 3 . To describe dentofacial morphological patterns of males with and without crowding or spacing; 4. To make a priori conclusions about affecting factors that might be associated with spacing and crowding.

\section{Materlals and Methods}

Full anthropometrical data of head and face measurements of 111 males aged 20.0 2.1 years was selected from records obtained as part of a larger ongoing study. These were used to investigate relationships between dentofacial and postcranial morphology according to individual orthodontic condition. $81.4 \%$ of participants were Russians from different regions of the Russian Federation, and $18.6 \%$ were of other ethnicity, but all were Caucasian. Frequencies from different nations corresponded to a census of enumeration in 2002. None of the subjects had undergone previous orthodontic treatment. This age group was chosen because at this early mature stage growth organism is complete, head and face dimensions are stable, aging is not yet significant, and the DMFT index of caries, especially the number of missing teeth, remains low.

The DMFT index and the presence of crowding or spacing on the maxilla and mandible were assessed using dental casts. Even very small deviations from smooth dental arch, linear displacement of the anatomical contact points, like incisor inclinations, were attributed to crowding and the presence of any space between teeth was attributed to spacing. Other cases were considered as normal.

For each of three discriminant analyses three subgroups were formed, using the following grouping factors:

a) 1-spacing on both dental arches; 2-absence of crowding, spacing, rotation, or displacement of teeth on both dental arches; 3-crowding on both dental arches;

b) 1-spacing on mandible; 2-absence of crowding, spacing, rotation, or displacement of teeth on mandible; 3-crowding on mandible;

c) 1-spacing on maxilla; 2-absence of crowding, spacing, rotation, or displacement of teeth on maxilla; 3-crowding on maxilla.

Presence of spacing and crowding, along with normal dentition constitutes a contiguous variable-teeth size-dental 
arch size discrepancy. In our study we used them as one parametric variable with three possible values, called "orthodontic status" (OS). Note, that in one analysis we used OS on both dental arches, and we excluded subjects with different $O S$ on the maxilla and mandible to emphasize differences across subsamples, and to achieve better discrimination.

Descriptive statistics of measurements and several indices, including mean and standard deviation, were computed for each group. Two-sample t-tests were calculated to compare the means of different groups at a 95\% confidence interval. Discrimination between groups was performed by multivariate forward stepwise discriminant analysis based on Mahalonobis distances, using the program Statistica 6.0. Canonical discriminant analysis was used to visualize the patterns of variability in chosen groups and to show the location of each individual case in two-dimensional space of canonical roots. Only elemental variables were used in discriminant analyses to avoid high tolerance. In all statistical calculations casewise deletion of missing data was used.

\section{Results}

The average DMFT indexes for both arches $\left(\mathrm{DMFT}_{\text {total }}\right)$, for the maxilla (DMFT maxilla $_{\text {) }}$ and for the mandible (DMFT mandible ) were found on the models according to WHO methods (Table 1). The average $\mathrm{DMFT}_{\text {tota }}=3.57 \pm 2.45$ indicates that evidence of caries among young Russian men has a value comparable with that of developed countries such as the United Kingdom, Israel, and Australia (Richardson and McIntyre, 1996; SganCohen et al., 2000; Hopcraft and Morgan, 2003). 11.11\% of subjects were found caries-free and $54.63 \%$ had $\mathrm{DMFT}_{\text {total }}=3$.

\section{Statistical comparison of groups}

Descriptive statistics including mean and standard deviation were computed for each variable. Two-sample t-tests were calculated to compare the means of different groups at a $95 \%$ confidence interval. Statistical comparison of the groups is shown in Table 3. Many measurements exhibited statistically significant differences between the groups at $p<0.05$ level and some of them at $p<0.01$.

Distribution of cases among the groups is shown in Table 2.

\section{Correlations of measurements}

Correlations of measurements are shown in Table 4. Many significant positive and negative correlations were found between measurements and individual OS. Positive correlation means that the variable has a bigger value in the crowded group; negative correlation means that the variable has a bigger value in the spaced group.

High correlations between dimensions of dental arches and cranial measurements (unpublished data) along with moderate correlations between OS and craniofacial measurements are prerequisites for the existence of common growth and development factors for both morphological systems. The
Table 1 Index of caries DMFT

\begin{tabular}{l|c|c|c}
\hline & DMFT $_{\text {maxilla }}$ & DMFT $_{\text {mandible }}$ & DMFT $_{\text {total }}$ \\
\hline $\mathrm{N}$ & 111 & 111 & 111 \\
\hline Mean+SD & $1.37 \pm 1.41$ & $2.20 \pm 1.55$ & $3.57 \pm 2.45$ \\
\hline Min-Max & $0-7$ & $0-7$ & $0-14$ \\
\hline
\end{tabular}

Distribution of cases among the groups is shown in Table 2.

Table 2 Frequency of malocclusions (\%), N=111

\begin{tabular}{l|l|l}
\hline \multirow{2}{*}{ Mandible } & Spaced & 25.4 \\
& Normal & 27.6 \\
& Crowded & 47.0 \\
\hline \multirow{3}{*}{ Maxilla } & Spaced & 38.1 \\
& Normal & 32.8 \\
& Crowded & 29.1 \\
\hline \multirow{3}{*}{ Both arches have the same feature } & Spaced & 19.4 \\
& Normal & 16.4 \\
& Crowded & 20.9 \\
& Cr $\uparrow$ Sp* & 14.9 \\
\hline
\end{tabular}

*Spacing on one arch and crowding on another arch

presence of significant correlations of measurements with spacing and crowding, along with significant t-tests between groups, allows us to suppose that associations between patterns of craniofacial architecture and crowding or spacing will be found by discriminant analysis.

\section{Discriminant analysis \\ Forward stepwise discriminant analysis}

Forward stepwise discriminant analysis was performed using all variables to obtain better differentiations between groups. Although Wilk's Lambdas $(\lambda)$ of standard discriminant analysis were a bit smaller (which affords better discrimination), we used a forward stepwise discriminant analysis to decrease the number of variables in the model. Wilk's Lambdas $(\lambda)$ of three discriminant analyses are shown in Table 5. All analyses demonstrated highly significant levels of discrimination at $p<0.001$.

Using the further mentioned variables, $79.7 \%$ (2 arches), $61.0 \%$ (maxilla) and $68.0 \%$ (mandible) of the original grouped cases were correctly classified by each forward stepwise discriminant analysis (Table 6). Table 7 presents constants and Fisher's linear discriminant functions coefficients for all variables used in the models.

Table 8 presents mean values of discriminant analyses canonical variables. The difference of the first root between the centers of groups "spacing" and "norm" is 1.29SD, "spacing" and "crowding" is $2.8 \mathrm{SD}$, "norm" and "crowding" is $1.51 \mathrm{SD}$ in analysis using the OS of 2 arches (the same on both). The difference of root 1 between the centers of groups "spacing" and "norm" is 1.1 SD, "spacing" and "crowding" is $1.38 \mathrm{SD}$, 
Table 3-1 Descriptive statistics and paired $t$-test comparison of anthropometric measurements between groups with different $\mathrm{OS}^{1}$

\begin{tabular}{|c|c|c|c|c|c|c|c|c|c|c|c|}
\hline \multirow[b]{3}{*}{ Measurement } & \multicolumn{10}{|c|}{ Using OS of 2 arches together (same status on both) } & \multirow{3}{*}{$\begin{array}{c}t \text {-test is } \\
\text { significant }\end{array}$} \\
\hline & \multicolumn{2}{|c|}{$\begin{array}{l}1 \text { (Spaced) } \\
(\mathrm{N}=18)\end{array}$} & \multicolumn{2}{|c|}{$\begin{array}{c}2 \text { (Normal) } \\
(\mathrm{N}=16)\end{array}$} & \multicolumn{2}{|c|}{$\begin{array}{c}3 \text { (Crowded) } \\
(\mathrm{N}=23)\end{array}$} & \multicolumn{2}{|c|}{ All $(\mathrm{N}=111)$} & \multicolumn{2}{|c|}{$\begin{array}{c}\sum(1+2+3) \\
(\mathrm{N}=57)\end{array}$} & \\
\hline & Mean & SD & Mean & $\mathrm{SD}$ & Mean & $\mathrm{SD}$ & Mean & SD & Mean & SD & \\
\hline Age & 19.8 & 1.3 & 21.3 & 2.3 & 19.7 & 1.6 & 20.0 & 2.3 & 20.2 & 1.9 & \\
\hline girth of head ${ }^{2}$ & 57.4 & 0.8 & 56.4 & 1.5 & 56.2 & 1.3 & 56.4 & 1.4 & 56.6 & 1.3 & $1>2 *, 1>3 * *$ \\
\hline skin fold on cheek ${ }^{2}$ & 11.3 & 2.6 & 9.6 & 2.3 & 9.7 & 2.0 & 10.1 & 2.6 & 10.2 & 2.3 & \\
\hline head length $(g-o p)^{2}$ & 196.8 & 5.4 & 191.3 & 7.1 & 194.3 & 6.1 & 193.2 & 7.7 & 194.2 & 6.4 & $1>2 *$ \\
\hline head width (eu-eu) ${ }^{2}$ & 159.6 & 5.1 & 158.0 & 4.0 & 155.9 & 5.5 & 156.9 & 5.4 & 157.7 & 5.2 & $1>3 *$ \\
\hline head index $(($ eu-eu $) /(g-o p)) * 100$ & 81.2 & 4.1 & 82.7 & 2.8 & 80.3 & 3.8 & 81.3 & 3.9 & 81.3 & 3.8 & \\
\hline forehead width (ft-ft $)^{2}$ & 113.4 & 4.3 & 110.9 & 4.0 & 110.1 & 3.4 & 110.6 & 4.2 & 111.4 & 4.1 & $1>3 * *$ \\
\hline max width of eye-sockets $(e x-e x)^{2}$ & 110.5 & 4.0 & 111.1 & 4.5 & 107.5 & 4.6 & 108.1 & 4.6 & 109.4 & 4.6 & $1>3 *$ \\
\hline zygomatical diameter (zy-zy) ${ }^{2}$ & 148.0 & 6.3 & 145.6 & 3.9 & 142.4 & 4.2 & 143.5 & 5.2 & 145.1 & 5.4 & $1>3 * *$ \\
\hline gonial width (go-go) ${ }^{2}$ & 113.9 & 4.8 & 111.6 & 6.1 & 109.7 & 5.3 & 110.1 & 5.5 & 111.6 & 5.6 & $1>3 *$ \\
\hline lower jaw length (gn-go $)^{2}$ & 106.7 & 4.4 & 104.1 & 4.3 & 102.4 & 4.6 & 103.9 & 4.7 & 104.2 & 4.7 & $1>3 * *$ \\
\hline full face height (gn-tr) & 182.1 & 6.5 & 177.4 & 7.9 & 184.0 & 11.8 & 182.0 & 9.4 & 181.5 & 9.6 & \\
\hline mophological face height (gn-gl) & 124.0 & 4.6 & 121.5 & 6.3 & 124.7 & 7.6 & 124.3 & 6.0 & 123.6 & 6.4 & \\
\hline forehead height (go-tr) $)^{2}$ & 58.1 & 4.9 & 55.9 & 7.2 & 59.2 & 7.2 & 57.8 & 6.7 & 57.9 & 6.6 & \\
\hline horizontal face index $(($ gn-gl $) /($ zy-zy $)) * 100$ & 83.9 & 4.3 & 83.5 & 4.0 & 87.6 & 4.6 & 86.7 & 4.3 & 85.3 & 4.7 & $1<3 *$ \\
\hline nose height $(\mathrm{sn}-\mathrm{g})^{2}$ & 55.6 & 3.4 & 56.7 & 3.3 & 56.1 & 4.1 & 56.6 & 3.6 & 56.1 & 3.6 & \\
\hline sagittal nose height (sn-pn) ${ }^{2}$ & 25.0 & 2.6 & 25.9 & 2.9 & 25.1 & 2.4 & 25.2 & 2.9 & 25.3 & 2.6 & \\
\hline upper lip height (ls-sn) $)^{2}$ & 16.0 & 1.5 & 14.4 & 1.6 & 14.4 & 1.9 & 14.9 & 2.0 & 14.9 & 1.8 & $1>2 *, 1>3 * *$ \\
\hline medial vertical mandible height $(\mathrm{gn}-\mathrm{li})^{2}$ & 34.6 & 5.3 & 33.5 & 3.9 & 36.7 & 4.9 & 35.2 & 4.3 & 35.1 & 4.9 & \\
\hline lips height $(1 \mathrm{~s}-1 \mathrm{ii})^{2}$ & 17.8 & 2.9 & 17.0 & 2.9 & 17.6 & 3.4 & 17.8 & 3.1 & 17.5 & 3.1 & \\
\hline interorbital diameter (en-en) ${ }^{2}$ & 34.9 & 2.8 & 35.4 & 3.0 & 33.8 & 2.9 & 34.4 & 2.9 & 34.6 & 2.9 & \\
\hline pupil-pupil $^{2}$ & 59.4 & 3.0 & 60.2 & 3.2 & 58.7 & 3.4 & 59.1 & 3.0 & 59.3 & 3.2 & \\
\hline nose width (al-al) ${ }^{2}$ & 35.7 & 2.3 & 34.7 & 1.7 & 33.6 & 2.4 & 34.5 & 2.4 & 34.6 & 2.3 & $1>3 * *$ \\
\hline nose index $(($ al-al $) /($ sn-g $)) * 100$ & 64.4 & 5.8 & 61.4 & 4.5 & 60.3 & 6.6 & 61.2 & 5.8 & 61.9 & 6.0 & $1>3 *$ \\
\hline mouth width (ch-ch) ${ }^{2}$ & 51.2 & 2.9 & 50.8 & 3.4 & 49.2 & 3.1 & 50.0 & 3.3 & 50.3 & 3.2 & $1>3 *$ \\
\hline vertical face index $(($ gn-gl $) /($ gn-sn $) * 100$ & 0.55 & 0.03 & 0.53 & 0.02 & 0.55 & 0.03 & 0.55 & 0.02 & 0.55 & 0.03 & $1>2 *$ \\
\hline
\end{tabular}

$* p<0.05 ; * * p<0.01 .{ }^{1}$ Comparisons of groups at non-significant $p$-level are not shown in the table.

${ }^{2}$ These variables were later used in discriminant analyses. 
Table 3-2 Descriptive statistics and paired $t$-test comparison of anthropometric measurements between groups with different $\mathrm{OS}^{1}$

\begin{tabular}{|c|c|c|c|c|c|c|c|c|c|c|c|c|c|c|}
\hline \multirow{3}{*}{\begin{tabular}{r|} 
Group \\
Measurement
\end{tabular}} & \multicolumn{7}{|c|}{ Using OS of maxilla separately } & \multicolumn{7}{|c|}{ Using OS of mandible separately } \\
\hline & \multicolumn{2}{|c|}{$\begin{array}{l}1 \text { (Spaced) } \\
(\mathrm{N}=51)\end{array}$} & \multicolumn{2}{|c|}{$\begin{array}{l}2 \text { (Normal) } \\
(\mathrm{N}=43)\end{array}$} & \multicolumn{2}{|c|}{$\begin{array}{l}3 \text { Crowded }) \\
(\mathrm{N}=43)\end{array}$} & \multirow[t]{2}{*}{$\begin{array}{l}t \text {-test is } \\
\text { significant }\end{array}$} & \multicolumn{2}{|c|}{$\begin{array}{l}1 \text { (Spaced) } \\
(\mathrm{N}=34)\end{array}$} & \multicolumn{2}{|c|}{$\begin{array}{l}2(\mathrm{~N}=36) \\
(\text { Normal) }\end{array}$} & \multicolumn{2}{|c|}{$\begin{array}{c}3 \text { (Crowded) } \\
(\mathrm{N}=62)\end{array}$} & \multirow[t]{2}{*}{$\begin{array}{l}t \text {-test is } \\
\text { significant }\end{array}$} \\
\hline & Mean & SD & Mean & SD & Mean & SD & & Mean & SD & Mean & SD & Mean & SD & \\
\hline Age & 20.4 & 2.8 & 20.1 & 2.1 & 19.6 & 1.8 & & 20.8 & 3.1 & 19.8 & 2.2 & 19.8 & 1.9 & \\
\hline $\begin{array}{l}\text { skin fold on } \\
\text { cheek }^{2}\end{array}$ & 10.7 & 2.9 & 10.1 & 2.5 & 9.5 & 2.2 & & 11.1 & 2.8 & 9.4 & 2.3 & 10.1 & 2.6 & $1>2 *$ \\
\hline head length (g-op) ${ }^{2}$ & 192.9 & 8.2 & 193 & 8 & 193.9 & 6.6 & & 195.3 & 7.1 & 192.1 & 8 & 192.8 & 7.7 & $1>3 *$ \\
\hline $\begin{array}{l}\text { forehead width } \\
(\mathrm{ft}-\mathrm{ft})^{2}\end{array}$ & 111.6 & 4.8 & 109.6 & 3.6 & 109.9 & 3.5 & $1>2 *, 1>3 *$ & 111.9 & 4.1 & 109.7 & 4 & 110.2 & 4.1 & \\
\hline $\begin{array}{l}\text { max width of eye- } \\
\text { sockets (ex-ex) }\end{array}$ & 108.7 & 3.9 & 108.3 & 4.7 & 106.9 & 5.1 & $2>3^{*}, 1>3^{*}$ & 109.4 & 3.9 & 107.6 & 4.8 & 107.8 & 4.4 & $1>3 *$ \\
\hline $\begin{array}{l}\text { zygomatical } \\
\text { diameter }(z y-z y)^{2}\end{array}$ & 144.5 & 6.4 & 143.5 & 4 & 142.3 & 4.7 & $1>3 *$ & 145.7 & 6.1 & 142.7 & 5 & 142.8 & 4.7 & $1>3 * *$ \\
\hline $\begin{array}{l}\text { mophological face } \\
\text { height (gn-gl) }\end{array}$ & 124.9 & 5.4 & 123.7 & 6.5 & 124.1 & 6.3 & & 124.7 & 5.6 & 122.3 & 5.2 & 125.2 & 6.5 & \\
\hline $\begin{array}{l}\text { forehead height } \\
(\text { go-tr) })^{2}\end{array}$ & 58 & 5.5 & 57.4 & 6.8 & 57.8 & 8 & & 57.7 & 6.5 & 57.3 & 7.8 & 58 & 6.3 & \\
\hline $\begin{array}{l}\text { horizontal face } \\
\text { index }((\text { gn-gl }) / \\
(z y-z y))^{*} 100\end{array}$ & 86.5 & 4.5 & 86.3 & 4.6 & 87.2 & 3.9 & $2<3 *$ & 85.7 & 4.9 & 85.8 & 4.3 & 87.7 & 4 & $1<3^{*}, 2<3^{* *}$ \\
\hline nose height (sn-g) ${ }^{2}$ & 56.7 & 3.8 & 57 & 3.2 & 55.9 & 3.8 & & 56 & 3.3 & 56.6 & 3.2 & 56.8 & 4 & \\
\hline $\begin{array}{l}\text { sagittal nose height } \\
(\text { sn-pn })^{2}\end{array}$ & 25 & 2.6 & 25.4 & 3.1 & 25 & 2.6 & & 24.7 & 2.6 & 25.4 & 3.1 & 25.1 & 2.7 & \\
\hline $\begin{array}{l}\text { upper lip height } \\
(1 \mathrm{~s}-\mathrm{sn})^{2}\end{array}$ & 15.2 & 1.9 & 14.6 & 1.9 & 14.8 & 2.3 & $1>2 *$ & 15.4 & 1.7 & 14.8 & 1.9 & 14.7 & 2.2 & $1>3^{*}, 1>2^{*}$ \\
\hline $\begin{array}{l}\text { medial vertical } \\
\text { mandible height } \\
(\text { gn-li) })^{2}\end{array}$ & 35.1 & 4 & 34.7 & 4.1 & 35.5 & 4.7 & & 34.7 & 4.6 & 33.4 & 3.2 & 36.2 & 4.3 & $1<3^{*}, 2<3^{* *}$ \\
\hline
\end{tabular}


Table 3-2 Descriptive statistics and paired t-test comparison of anthropometric measurements between groups with different OS $^{1}$

\begin{tabular}{|c|c|c|c|c|c|c|c|c|c|c|c|c|c|c|}
\hline \multirow{3}{*}{$\begin{array}{r}\text { Group } \\
\text { Measurement }\end{array}$} & \multicolumn{7}{|c|}{ Using OS of maxilla separately } & \multicolumn{7}{|c|}{ Using OS of mandible separately } \\
\hline & \multicolumn{2}{|c|}{$\begin{array}{c}1 \text { (Spaced) } \\
(\mathrm{N}=51)\end{array}$} & \multicolumn{2}{|c|}{$\begin{array}{c}2 \text { (Normal) } \\
(\mathrm{N}=43)\end{array}$} & \multicolumn{2}{|c|}{$\begin{array}{c}3 \text { Crowded) } \\
(\mathrm{N}=43)\end{array}$} & \multirow[t]{2}{*}{$\begin{array}{l}t \text {-test is } \\
\text { significant }\end{array}$} & \multicolumn{2}{|c|}{$\begin{array}{c}1 \text { (Spaced) } \\
(\mathrm{N}=34)\end{array}$} & \multicolumn{2}{|c|}{$\begin{array}{l}2(\mathrm{~N}=36) \\
\text { (Normal) }\end{array}$} & \multicolumn{2}{|c|}{$\begin{array}{c}3 \text { (Crowded) } \\
(\mathrm{N}=62)\end{array}$} & \multirow[t]{2}{*}{$\begin{array}{c}t \text {-test is } \\
\text { significant }\end{array}$} \\
\hline & Mean & SD & Mean & SD & Mean & SD & & Mean & SD & Mean & SD & Mean & SD & \\
\hline lips height (ls-li) $)^{2}$ & 17.9 & 2.8 & 17.5 & 3.5 & 17.9 & 3.2 & & 18.5 & 3.1 & 17.4 & 2.6 & 17.6 & 3.4 & \\
\hline $\begin{array}{l}\text { interorbital } \\
\text { diameter (en-en) }\end{array}$ & 34.3 & 2.5 & 34.8 & 3.1 & 33.8 & 2.9 & & 34.7 & 2.7 & 34 & 2.8 & 34.3 & 3 & \\
\hline pupil-pupil $^{2}$ & 59.2 & 2.8 & 59.2 & 3.3 & 58.7 & 3.2 & & 59.3 & 3.1 & 59.3 & 3 & 58.8 & 3.1 & \\
\hline $\begin{array}{l}\text { nose width } \\
(\text { al-al })^{2}\end{array}$ & 34.7 & 2.4 & 34.8 & 2.5 & 33.9 & 2.2 & $1>3 *$ & 35 & 2.5 & 34.7 & 2.1 & 34.1 & 2.4 & $1>3 *, 2>3 *$ \\
\hline $\begin{array}{l}\text { nose index } \\
((\text { al-al }) /(\text { sn-g }))^{*} \\
100\end{array}$ & 61.5 & 6.4 & 61.2 & 5.4 & 60.6 & 5.5 & & 62.7 & 6.2 & 61.4 & 4.3 & 0.2 & 6.2 & $1>3 * *$ \\
\hline $\begin{array}{l}\text { mouth width } \\
(\text { (ch-ch) })^{2}\end{array}$ & 50.4 & 3.4 & 50 & 3.2 & 49.5 & 3.1 & & 51.1 & 3 & 50 & 3.3 & 49.5 & 3.3 & $1>3 * *$ \\
\hline $\begin{array}{l}\text { vertical face } \\
\text { index }((\mathrm{gn}-\mathrm{gl}) / \\
(\mathrm{gn}-\mathrm{sn}) * 100\end{array}$ & 0.55 & 0.02 & 0.54 & 0.02 & 0.55 & 0.03 & & 0.55 & 0.02 & 0.54 & 0.02 & 0.55 & 0.03 & $1>2 *$ \\
\hline
\end{tabular}

$* p<0.05 ; * *<<0.01 .{ }^{1}$ Comparisons of groups at non-significant $p$-level are not shown in the table.

${ }^{2}$ These variables were later used in discriminant analyses.

Ågnorm" and "crowding" is $0.37 \mathrm{SD}$ in analysis using the OS of the maxilla. The difference of root 1 between the centers of groups "spacing" and "norm" is $1.14 \mathrm{SD}$, "spacing" and "crowding" is $2.1 \mathrm{SD}$, "norm" and "crowding" is $0.96 \mathrm{SD}$ in analysis using the OS of the mandible. The differences of the second root in all analyses ranged from 1.1 SD to $1.39 \mathrm{SD}$. It describes only from $20.0 \%$ to $38.2 \%$ of variation and will not be taken into consideration in our paper. Scatterplots of canonical scores of each case are shown in Figs 1, 2, and 3.

Among the measurements, 10 variables were chosen in the model by canonical discriminant analysis using the OS of 2 arches (Table 9). The first root describes $80.0 \%$ of total variation and can be morphologically interpreted. In the group "spacing," girth of head, zygomatic width, nose width, forehead width, gonial width, and height of upper lip are enlarged and combined with slightly reduced medial vertical mandible height. Enlarging of face diameters is observed; this is not due to the tendency of this group to increased development of adipose tissue, but results from increased growth of the skull in the horizontal plane, since the skin fold on the cheek was not chosen for the model by this particular analysis. So here we can see the combination of a wide face with shortened height of the mandible and a higher maxilla.

In the group "crowding," increased height of the lower jaw and decreased height of the upper lip in combination with a narrow face are marked. In this group, the tendency to higher development of bony tissue of the postcranial skeleton is presented (unpublished data). This could be an explanation for the observed form of the mandible which is more associated with somatic type of growth within the craniofacial complex. The group "normal" has a well-balanced face. We propose to name this the "harmonious type of face." Notable is that the normal group has much less intragroup variability in comparison with the spaced or crowded groups (Fig. 1). This may occur due to a better morpho-functional balance of the craniofacial complex of that group as a base for OS.

Ten variables were chosen in the model by canonical discriminant analysis using the OS of the maxilla. The first root describes $61.8 \%$ of total variation and has the following interpretation. In the group "spacing," head width, forehead width, maximum width of eye-sockets, upper lip height, nose width, lower jaw length, and girth of head are enlarged and combined with slightly reduced medial vertical mandible height. We can see almost the same tendency, as in the previous analysis: a wide face with a wide nose and high upper lip is combined with shortened height of the mandible in the spaced group and vise versa in the crowded group.

12 variables were chosen in the model by canonical discriminant analysis using the OS of the mandible. The first root describes $79.0 \%$ of total variation. In the group "spacing," zygomatic width, forehead width, mouth width, upper lip height, girth of head, head length, and lower jaw length are enlarged and combined with slightly reduced medial vertical mandible height. We can see the same tendency, as in two 
Table 4 Pearson's correlation coefficients of the measurements with OS, used in discriminant analyses of samples with the same OS on both of the 2 arches, with OS of the maxilla and OS of the mandible

\begin{tabular}{|c|c|c|c|c|c|c|}
\hline & $\begin{array}{c}\text { OS of } \\
2 \text { arches } N=57\end{array}$ & $p$ & $\begin{array}{c}\text { OS of } \\
\text { maxilla } N=111\end{array}$ & $p$ & $\begin{array}{c}\text { OS of } \\
\text { mandible } \mathrm{N}=111\end{array}$ & $p$ \\
\hline girth of head $^{1}$ & -0.39 & 0.003 & -0.30 & 0.003 & -0.23 & 0.023 \\
\hline skin fold on cheek ${ }^{1}$ & -0.28 & 0.035 & -0.12 & 0.228 & -0.19 & 0.068 \\
\hline head length (g-op) ${ }^{1}$ & -0.15 & 0.274 & -0.20 & 0.054 & -0.01 & 0.934 \\
\hline head width (eu-eu) ${ }^{1}$ & -0.31 & 0.018 & -0.21 & 0.036 & -0.30 & 0.003 \\
\hline head index $(($ eu-eu $) /(g-o p)) * 100$ & -0.12 & 0.385 & 0.02 & 0.820 & -0.19 & 0.063 \\
\hline forehead width $(\mathrm{ft}-\mathrm{ft})^{1}$ & -0.34 & 0.009 & -0.18 & 0.076 & -0.24 & 0.017 \\
\hline max width of eye-sockets $(\text { ex-ex })^{1}$ & -0.29 & 0.027 & -0.21 & 0.036 & -0.21 & 0.039 \\
\hline zygomatical diameter (zy-zy) & -0.44 & 0.001 & -0.34 & 0.001 & -0.24 & 0.018 \\
\hline gonial width (go-go) ${ }^{1}$ & -0.32 & 0.017 & -0.14 & 0.168 & -0.19 & 0.063 \\
\hline lower jaw length (gn-go) ${ }^{1}$ & -0.38 & 0.004 & -0.23 & 0.023 & -0.28 & 0.006 \\
\hline full face height (gn-tr) & 0.10 & 0.451 & 0.10 & 0.326 & 0.03 & 0.797 \\
\hline mophological face height (gn-gl) & 0.06 & 0.637 & 0.12 & 0.235 & 0.01 & 0.955 \\
\hline forehead height (go-tr) ${ }^{1}$ & 0.09 & 0.527 & 0.03 & 0.796 & 0.03 & 0.768 \\
\hline horizontal face index $(($ gn-gl $) /(z y-z y)) * 100$ & 0.35 & 0.007 & 0.34 & 0.001 & 0.16 & 0.118 \\
\hline nose height (sn-g) ${ }^{1}$ & 0.05 & 0.713 & 0.13 & 0.205 & -0.04 & 0.695 \\
\hline sagittal nose height (sn-pn) ${ }^{1}$ & 0.01 & 0.958 & 0.07 & 0.486 & 0.04 & 0.698 \\
\hline upper lip height (1s-sn) ${ }^{1}$ & -0.36 & 0.006 & -0.21 & 0.034 & -0.14 & 0.187 \\
\hline medial vertical mandible height (gn-li) ${ }^{1}$ & 0.20 & 0.143 & 0.26 & 0.009 & 0.09 & 0.363 \\
\hline lips height (ls-li) ${ }^{1}$ & -0.02 & 0.864 & -0.16 & 0.118 & 0.01 & 0.925 \\
\hline interorbital diameter (en-en) ${ }^{1}$ & -0.16 & 0.227 & -0.05 & 0.610 & -0.12 & 0.255 \\
\hline pupil-pupil ${ }^{1}$ & -0.10 & 0.442 & -0.05 & 0.640 & -0.08 & 0.414 \\
\hline nose width $(\text { al-al })^{1}$ & -0.38 & 0.000 & -0.29 & 0.004 & -0.24 & 0.016 \\
\hline nose index $(($ al-al $) /($ sn-g) $) * 100$ & -0.29 & 0.029 & -0.28 & 0.006 & -0.14 & 0.160 \\
\hline mouth width (ch-ch) ${ }^{1}$ & -0.28 & 0.037 & -0.25 & 0.014 & -0.03 & 0.739 \\
\hline vertical face index $(($ gn-gl $) /($ gn-sn $) * 100$ & 0.00 & 0.985 & -0.04 & 0.682 & 0.04 & 0.672 \\
\hline
\end{tabular}

${ }^{1}$ These variables were later used in discriminant analyses; significant correlations are marked in bold. 
Table 5 Discriminant analyses: Wilk's Lambdas $(\lambda)$

\begin{tabular}{|c|c|c|c|c|c|c|c|c|}
\hline \multicolumn{9}{|c|}{ Grouping variable: } \\
\hline \multicolumn{3}{|c|}{$\begin{array}{l}\text { OS of } 2 \text { arches (the same on both) } \\
\qquad N=57\end{array}$} & \multicolumn{3}{|c|}{$\begin{array}{l}\text { OS of maxilla } \\
\qquad \mathrm{N}=97\end{array}$} & \multicolumn{3}{|c|}{$\begin{array}{l}\text { OS of mandible } \\
\quad \mathrm{N}=97\end{array}$} \\
\hline$\lambda$ & $p<$ & $\mathrm{F}$ & $\lambda$ & $p<$ & $\mathrm{F}$ & $\lambda$ & $p<$ & $\mathrm{F}$ \\
\hline 0.29 & 0.0000 & $F(20.9)=3.79$ & 0.59 & 0.0006 & $F(20.17)=2.55$ & 0.47 & 0.0000 & $F(24.17)=3.16$ \\
\hline
\end{tabular}

Table 6 Classification results of forward stepwise discriminant analyses

\begin{tabular}{c|c|c|c|c}
\hline Groups & Original group count & Predicted group membership \\
\hline \multicolumn{5}{c}{$\begin{array}{r}\text { Grouping variable: OS of } 2 \text { arches } \\
\text { (the same on both) }\end{array}$} \\
\hline Spaced & 72.2 & 13 & 2 & 3 \\
\hline Normal & 76.5 & 3 & 13 & 1 \\
\hline Crowded & 87.5 & 1 & 2 & 21 \\
\hline Total & 79.7 & 17 & 17 & 25 \\
\hline
\end{tabular}

Grouping variable: OS of maxilla

\begin{tabular}{l|c|c|c|c}
\hline & Percentage & Spaced & Normal & Crowded \\
\hline Spaced & 68.4 & 26 & 4 & 8 \\
\hline Normal & 56.3 & 8 & 18 & 6 \\
\hline Crowded & 56.7 & 7 & 6 & 17 \\
\hline Total & 61.0 & 41 & 28 & 31 \\
\hline
\end{tabular}

Grouping variable: OS of mandible

\begin{tabular}{l|c|c|c|c}
\hline & Percentage & Spaced & Normal & Crowded \\
\hline Spaced & 66.7 & 16 & 4 & 4 \\
\hline Normal & 42.9 & 4 & 12 & 12 \\
\hline Crowded & 83.3 & 4 & 4 & 40 \\
\hline Total & 68.0 & 24 & 20 & 56 \\
\hline
\end{tabular}

previous analyses, with the addition of a prolonged lower jaw, high nose, and wide mouth. A wide high upper lip is combined with shortened height of the mandible in the spaced group and vise versa in the crowded group.

\section{Discussion}

Organisms must be analysed as integrated wholes, with Bauplane so constrained by phyletic heritage, pathways of development and general architecture.

S. Gould and R. Lewontin 1979

Many attempts have been made to find causes of crowding and correlate this condition of dental apparatus with anthropometrical parameters of human jaws, skulls and, much more rarely, body shapes.

The genetic and environmental basis of occlusion variation has been discussed for more than a hundred years. Many theories have been put forth to explain the high prevalence of dental crowding in modern civilized populations. Studies have adopted various methodologies and many contradictory conclusions have been reached.

This could be due to a lack of comprehensive studies on the heterochrony of human skull development and its causes. In our opinion, genetic and environmental aspects of variation can not be easily separated and indicated, as many authors suppose, even using twin data, because many additional hidden factors cannot be observed, estimated, and taken into consideration.

All available studies on the subject were performed using radiograms implicating mostly profile measurements. Another disadvantage of this method is exposure. The rate of subjects' agreement to participate in lateral cephalograms, posterioanterior skull radiograms, and panoramic films for study purposes is only $41.7 \%$ (Johannsdottir et al., 2004). That is why only cephalograms made for treatment purposes are usually available for research. This limits the validity of data because the sample is not randomized and is influenced by health status.

In this study we used a method of anthropometrical measurement which does not share the limitations of radiograms. In our study the rate of refusal to participate was $0.9 \%$ ( 1 of 112 participants). The resulting sample was random and matched by age because it was collected during temporary military service. We used mostly measurements of the frontal plane of the skull; the only 3 measurements were in the sagittal plane (head length (g-op), sagittal nose height (sn-pn), and mandible corpus length (gn-go)). We found that all canonical discriminant analyses accord with each other and the results do not depend on grouping factors and sample size.

Our results and those published previously by Driscoll- 
Table 7 Variables in the model and classification discriminant functions

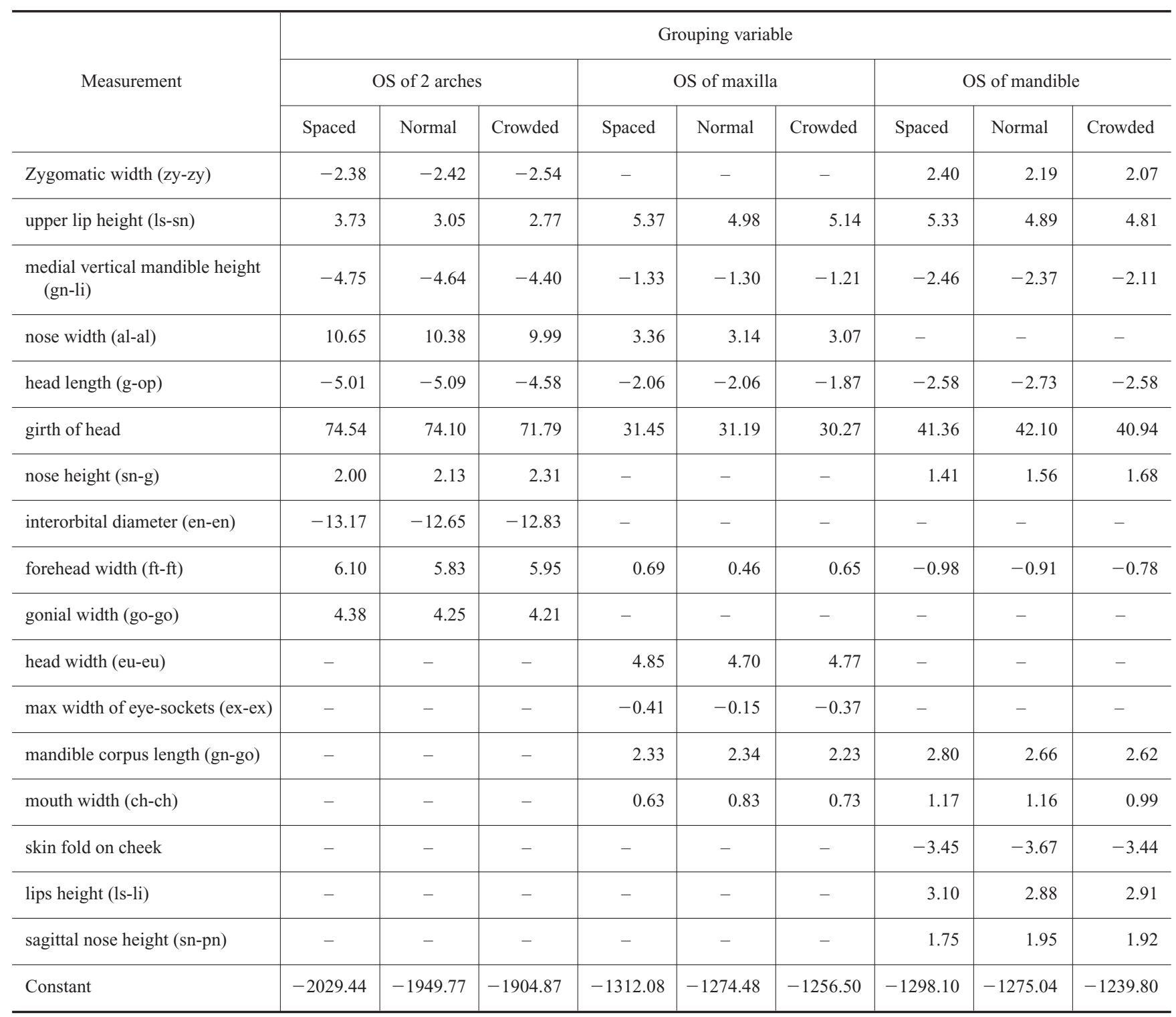

- variable is not in the model

Table 8 Means of canonical discriminant analyses canonical variables

\begin{tabular}{l|c|c|c|c|c|c}
\hline $\begin{array}{l}\text { Grouping } \\
\text { variable: }\end{array}$ & \multicolumn{2}{|c|}{$\begin{array}{c}\text { OS of 2 arches } \\
\text { (same on both) }\end{array}$} & \multicolumn{2}{c|}{ OS of maxilla } & \multicolumn{2}{c}{ OS of mandible } \\
\hline Group & $\begin{array}{c}\text { Root 1 } \\
\text { Mean }\end{array}$ & $\begin{array}{c}\text { Root 2 } \\
\text { Mean }\end{array}$ & $\begin{array}{r}\text { Root 1 } \\
\text { Mean }\end{array}$ & $\begin{array}{c}\text { Root 2 } \\
\text { Mean }\end{array}$ & $\begin{array}{c}\text { Root 1 } \\
\text { Mean }\end{array}$ & $\begin{array}{c}\text { Root 2 } \\
\text { Mean }\end{array}$ \\
\hline Spaced & 1.49 & 0.45 & -0.74 & -0.14 & -1.31 & 0.37 \\
\hline Normal & 0.20 & -0.94 & 0.27 & 0.67 & -0.17 & -0.73 \\
\hline Crowded & -1.31 & 0.30 & 0.64 & -0.49 & 0.79 & 0.23 \\
\hline
\end{tabular}

Gilliland et al. (2001) show that changes in lower incisor crowding in adults and adolescents were related to growth in the vertical dimension. What reasons can we presume for the existence of typical face patterns connected to different OS?

We conclude that developing a precise OS is a product of interactions during the ontogenesis of jaw between the time of teeth eruption and growth along two growth fields (alveolar and corpus). Likewise Gould and Lewontin (1979) considered the chin to be a product of interaction between growth of the alveolar processes and the corpus of the mandible. Mostly, previous studies dealt with mandibular crowding, although some growth changes were described for the maxilla.

As previously demonstrated, humans have a growth-maturity gradient across multiple craniofacial measurements, with the most mature components associated with neural growth 


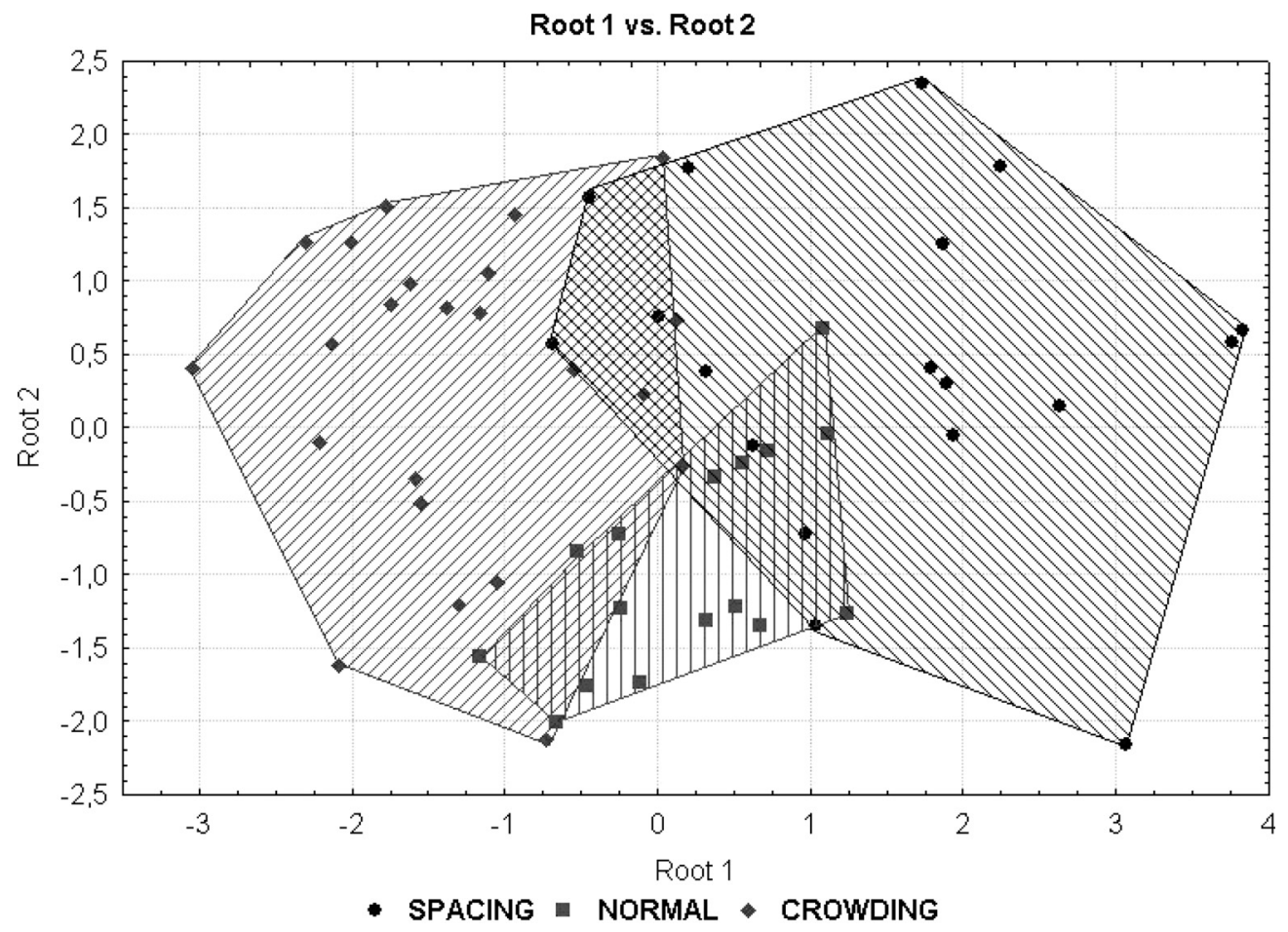

Fig. 1 Canonical discriminant analysis of head and face measurements, grouping variable-OS of both dental arches.

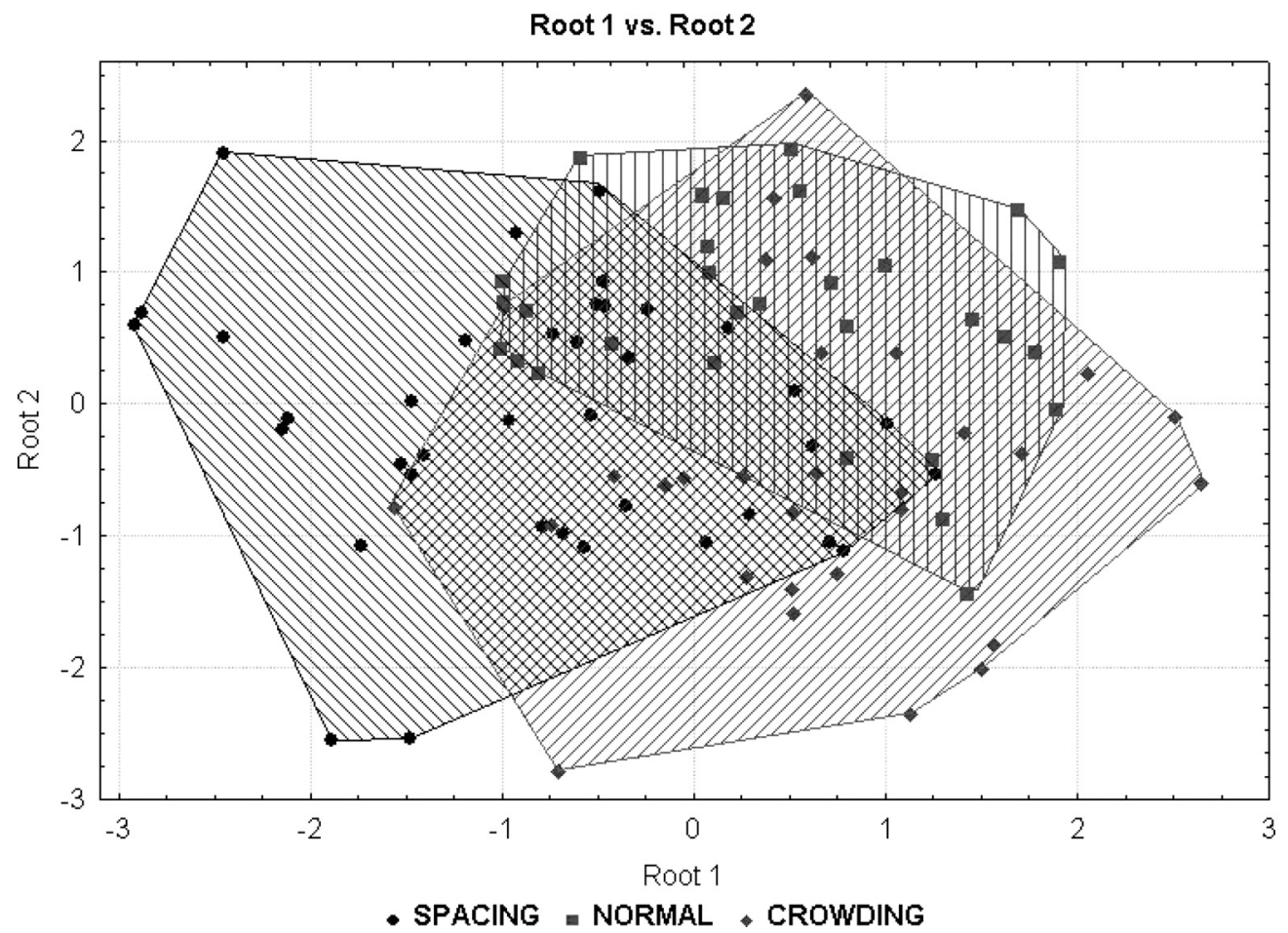

Fig. 2 Canonical discriminant anaiysia of head and face measurements, grouping variable-OS of maxilla. 


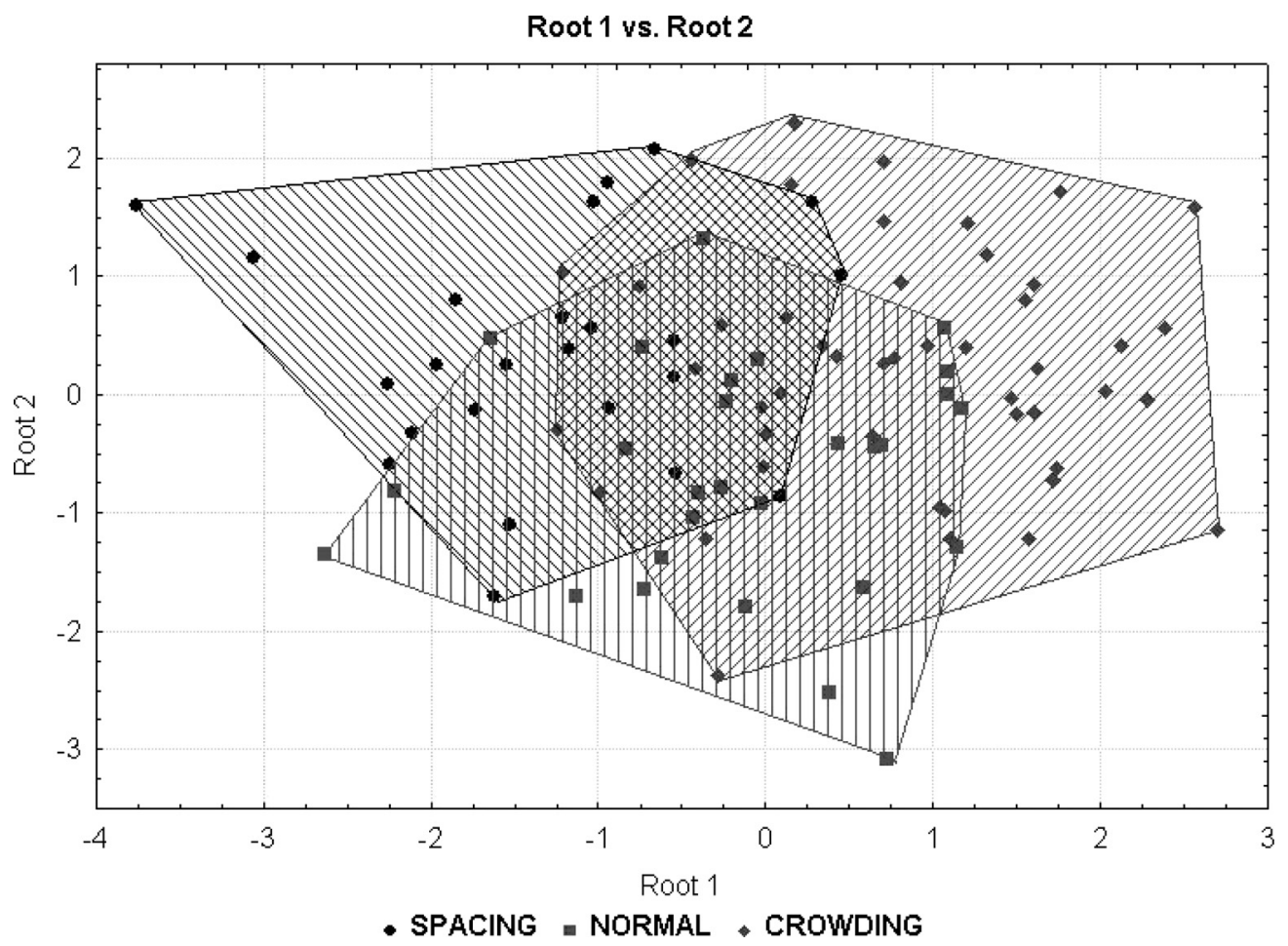

Fig. 3 Canonical discriminant anaiysia of head and face measurements, grouping variable-OS of mandible.

(neurocranial), the least mature associated with somatic growth (mandible), and viscerocranial growth falling somewhere between these two. Tanner (1962), Buschang et al. (1983), and Thilander (1995) postulated that the craniofacial complex expresses a continuous pattern of variation in maturity, or differential growth, and called this the craniofacial growth maturity gradient. This variation in maturity is manifest between structures as relative maturity (i.e., percentage of adult status attained) for a particular structure at a given time. In this context, less mature structures would be expected to grow more rapidly at a given time than more mature structures under the factors which affect growth rate and velocity, for example human growth hormone (GH).

Animal studies show that measures (body weight, limb measures, posterior mandible corpus length, ramus height, and nasal length) with the greatest overall absolute and relative growth potential showed the largest response to $\mathrm{GH}$ supplementation: i.e., the least mature components had the greatest treatment effects. It was interesting that $\mathrm{GH}$ altered the growth rate even in measures presumed to have relatively little response to GH during this time span. In three measures (total mandibular length, ramus height, and posterior neurocranial height), the stimulation was very great, whereas, for the other 2 (anterior mandibular corpus length and occipital length), it was much more modest (Vandeberg et al., 2004; Singleton et al., 2006). Likewise, insults or therapy might produce differing results based on the relative maturity of the structure (Douglas et al., 2005).

Development of dentition is an integral part of craniofacial growth, even though it is not closely related to other maturational processes. Teeth eruption and dental age seem little affected, while dental maturation does not appear to be influenced by GH. In contrast to skeletal maturation, dental age was not delayed in patients with dwarfism. The general growth retardation is, apparently, reflected to a differential extent within the craniofacial complex, while dental maturation appears to be a distinct process tightly linked to chronological age and independent of general growth, bone age, and GH influence (Van Erum et al., 1997, 1998a 1998b; Haas et al., 2001). Formation and eruption of teeth are processes that are not closely related to general growth. In contrast to dental maturation, bone maturation was delayed in the majority of the studied cases. Low correlations also have been reported between dental and skeletal ages in "normal" subjects (Demirjian et al., 1985; Lewis, 1991).

Here we found an excellent explanation of face pattern connected to crowding: the relatively high medial vertical mandible height (gn-li) in combination with a long and narrow face. We assume that the posterior part of the mandibular corpus and alveolar process, and the mandibular ramus, were affected in more different ways during ontogenesis by human $\mathrm{GH}$ than the anterior part of the mandibular corpus and anterior part of the alveolar process in combination with normal changing to permanent dentition in accordance with chronological age. This is confirmed by the study of Corruccini and Potter (1980) who found that the posterior (postcanine) and anterior (canine and incisor) components of the dental arch behave differently from each other. Additional 
Table 9 Factor structure of canonical discriminant analyses

\begin{tabular}{|c|c|c|c|c|c|c|}
\hline \multirow{2}{*}{ Measurement } & \multicolumn{2}{|c|}{ OS of 2 arches } & \multicolumn{2}{|c|}{ OS of maxilla } & \multicolumn{2}{|c|}{ OS of mandible } \\
\hline & Root 1 & Root 2 & Root 1 & Root 2 & Root 1 & Root 2 \\
\hline zygomatic width (zy-zy) & 0.41 & -0.02 & & & -0.43 & 0.09 \\
\hline upper lip height (1s-sn) & 0.32 & 0.40 & -0.30 & -0.32 & -0.26 & 0.23 \\
\hline medial vertical mandible height (gn-li) & -0.17 & 0.32 & 0.10 & -0.27 & 0.31 & 0.38 \\
\hline nose width (al-al) & 0.34 & 0.01 & -0.38 & 0.21 & - & - \\
\hline head length (g-op) & 0.12 & 0.53 & -0.07 & -0.28 & -0.24 & 0.26 \\
\hline girth of head & 0.34 & 0.25 & -0.42 & -0.08 & -0.36 & 0.03 \\
\hline nose height (sn-g) & -0.04 & -0.17 & - & - & 0.16 & -0.21 \\
\hline diameter (en-en) & 0.14 & -0.27 & - & - & & \\
\hline forehead width (ft-ft) & 0.30 & 0.19 & -0.45 & -0.11 & -0.22 & 0.17 \\
\hline gonial width (go-go) & 0.27 & 0.05 & - & - & - & - \\
\hline head width (eu-eu) & - & - & -0.53 & 0.02 & - & - \\
\hline max width of eye-sockets (ex-ex) & - & - & -0.28 & 0.43 & - & - \\
\hline mandible corpus length (gn-go) & - & - & -0.44 & 0.23 & -0.28 & 0.10 \\
\hline mouth width (ch-ch) & - & - & -0.01 & 0.22 & -0.29 & -0.20 \\
\hline skin fold on cheek & - & - & - & - & -0.16 & 0.51 \\
\hline lips height (ls-li) & - & - & - & - & -0.19 & 0.23 \\
\hline sagittal nose height (sn-pn) & - & - & - & - & 0.09 & -0.34 \\
\hline variation explained (\%) & 80.0 & 20.0 & 61.8 & 38.2 & 79.0 & 21.0 \\
\hline
\end{tabular}

- variable is not in the model

confirmation is provided by Tata (1976), who reports that in common with other growth-promoting hormones, peptide hormones (including GH) evoke multiple biochemical responses in their target tissues. These can be divided into two groups: (a) rapid effects involving permeability properties of the target cell to amino acids, sugars, and ions or changes in key intracellular metabolites, like cyclic nucleotides; (b) slow responses based on the stimulation of RNA and protein synthesis. He suggests that more than one species of hormone receptor exists and that the final expression of growth and maturation results from the cooperative interaction of rapid and slow responses of the target cell to the hormone (Tata, 1976).

The opposite trait, spacing, may occur in slightly low level GH individuals with sufficient growth of the anterior alveolar component, which is connected with the whole widthdirectional growth of the face.

$\mathrm{GH}$ is thought to begin to influence growth by 9 months of age in humans. Because GH is known to be a potent stimulator of cartilage-mediated growth, most previous studies have attributed its growth-promoting effects to its action on interstitial growth at cartilaginous growth centers. Although this effect is undoubtedly important, the results of Douglas et al. (2005) suggest that GH also stimulates growth of measures that primarily involve intramembranous or sutural growth. In Van Erum et al.'s (1998) study of craniofacial growth, in GHtreated children born small for gestational age, high-dose GH supplementation over a 2-year period led to significant craniofacial catch-up growth, particularly in posterior total facial height, cranial base length, and overall mandibular length. These measurements also demonstrated an agedependent effect of the treatment on velocity: i.e., the younger the age, the more pronounced the effect. Craniofacial growth, and particularly growth of the neurocranium, would be affected differently than if therapy began during or before puberty (Van Erum et al., 1998). The other extreme case, acromegaly, 
represents an endocrine disease which includes somatic and metabolic disorders secondarily resulting from augmentation of GH secretion after growth cartilages close (in adults). Pituitary gland disease and GH deficiency induce changes in various vital organs. Among them is a change in occlusion. As a result, the craniofacial skeleton has a specific configuration, the mandible is developed to excess and relationships between the maxilla, the mandible, and the skull are strongly modified. These, along with structural bony troubles and bony asymmetries, involve periodontal, muscular, and articular disturbances (Morarasu et al., 1997).

We propose that during the individual's ontogenesis of the jaws a discrepancy between the dental arch size and the sum of mesiodistal diameters of teeth may occur as a result of heterochrony of evolutionary reduction as well as of individual growth or because of the interaction of two. The dependence of the $\mathrm{GH}$ effect on relative maturity suggests that different craniofacial morphologies may result depending on the timing of the GH peak during adolescence and its interactions with other hormones such as sex or thyroid hormones. It was confirmed that thyroxin augments the effect of growth hormone on the mandibular condyle just as at other osteogenetic centers, for example the proximal tibial epiphysis (Hoskins and Asling, 1997). Biologically important interrelations exist between GH and sex hormones. They are operative not only at the pituitary and gonadal levels but also in peripheral tissues, where sex hormones modify the metabolic and growth-promoting effects of $\mathrm{GH}$. GH is also important for an optimal androgenic effect of testosterone in the development of secondary sexual characteristics (Zachmann, 1992).

Individual OS may depend on the mechanical forces of the masseter, human $\mathrm{GH}$, and other growth-promoting hormone titers, interactions of hormones during ontogenesis, and individual hormonal profiles, velocity of maturation, and tissue receptor sensitivity to growth-promoting hormones in different parts of the jaws. In other words, the heterochrony may occur between the bone and dental maturation, resulting from some disbalance or disorder in the growing organism. It can also be a mark of the microevolutionary process in contemporary human populations. In modern settings, it is not necessary to perform considerable mastication and may need higher functional loads on the masticatory apparatus to improve its development and balance.

Last, we must draw attention to the fact that the group with both normal dental arches has much less intragroup variability in comparison with groups with spacing on both arches or crowded on both arches (Fig. 1). This may be due to better morpho-functional balance of the craniofacial complex of that group as a base for a good OS. From the other side, the development of spacing or crowding can be the result of heterochrony and different rates of reduction of teeth, alveolar process, and mandibular corpus during phylo- and ontogenesis.

\section{Conclusion}

1. Many significant positive and negative correlations were found between craniofacial measurements and individual OS.

2. Many measurements exhibited statistically significant differences between the groups with different OS at the $p<0.05$ level and some of them - at $p<0.01$.

3. Using forward stepwise discriminant analysis, a high difference in craniofacial architecture between the groups with different OS was found. Canonical discriminant analysis indicates the face pattern connected to crowding: relatively high medial vertical mandible height in combination with a vertically long and narrow face; and to spacing: a wide face with wide nose and high upper lip is combined with shortened medial vertical mandible height.

4. Depending on the grouping factor, 10 to 12 variables were chosen in the canonical discriminant model. Classification functions and means of canonical roots were calculated; morphological interpretations of canonical roots were performed.

5. Definitive OS is a complicated product of interaction during the individual's ontogenesis of the jaws between the time of teeth eruption and the growth of two growth fields (alveolar and corpus) under the simultaneous influence of hormonal status and the chronological age of the individual. It can be also a mark of microevolutionary processes in contemporary human populations.

\section{References}

Andrik P (1963) Die Entwicklung der Bissomalien vom Neolithikum bis zur Gegenwart. Fortschritte der Kieferorthopädie 24: 12-21 [In German]

Behrents RG, Johnston LE Jr (1984) The influence of the trigeminal nerve on facial growth and development. Am J Orthod 85: 199-206

Berg R (1986) Crowding of the dental arches: a longitudinal study of the age period between 6 and 12 years. Eur J Orthod 8: 43-49

Bishara SE, Jakobsen JR (1985) Longitudinal changes in three normal facial types. Am J Orthod 88: 466-502

Bishara SE, Jakobsen JR, Hession TJ, Treder JE (1998a) Soft tissue profile changes from 5 to 45 years of age. Am J Orthod Dentofacial Orthop 114: 698-706

Bishara SE, Jakobsen JR, Nowak A (1998b) Arch length changes from 6 weeks to 45 years. Angle Orthod 68: 69-74

Bishara SE, Khadivi P, Jakobsen JR (1995) Changes in tooth size-arch length relationships from the deciduous to the permanent dentition: a longitudinal study. Am J Orthod Dentofacial Orthop 108: 607-613

Bjork A (1963) Variations in the growth pattern of the human mandible. Longitudinal radiographic study by the implant 
method. J Dent Res 42: 400-411

Brader AC (1972) Dental arch form related with intraoral forces: PR=C. Am J Orthod 61: 541-561

Brash JC (1956) The aetiology of irregularity and malocclusion of the teeth. Arch Oral Biol 9: 314-316

Buschang PH, Baume RM, Nass GG (1983) Craniofacial growth and size patterns during postnatal development. Growth 47: 217-223

Cherdantsev VG (2003) Morphogenesis and evolution. KMK, Moscow, 360 [In Russian]

Chvatal BA, Behrents RG, Ceen RF, Buschang PH (2005) Development and testing of multilevel models for longitudinal craniofacial growth prediction. Am J Orthod Dentofacial Orthop 128: 45-56

Corruccini RS, Potter RH (1980) Genetic analysis of occlusal variation in twins. Am J Orthod 78: 140-154

Demirjian A, Buschang PH, Tanguay R, Patterson DK (1985) Interrelationships among measures of somatic, skeletal, dental, and sexual maturity. Am J Orthod 88: 433-438

Doris JM, Bernard BW, Kuftinec MM (1981) A biometric study of tooth size and dental crowding. Am J Orthod 79: 326-336

Driscoll-Gilliland J, Buschang PH, Behrents RG (2001) An evaluation of growth and stability in untreated and treated subjects. Am J Orthod Dentofacial Orthop 120: 588-597

Farella M, Michelotti A, Carbone G, Gallo LM, Palla S, Martina R (2005) Habitual daily masseter activity of subjects with different vertical craniofacial morphology. Eur J Oral Sci 113: 380-385

Gould SJ, Lewontin RC (1979) The spandrels of San Marco and the Panglossian paradigm: a critique of the adaptationist program. Proc Royal Soc of London B 205; 1161: 581-598

Haas AD, Simmons KE, Davenport ML, Proffit WR (2001) The effect of growth hormone on carniofacial growth and dental maturation in Turner syndrome. Angle Orthod 71: 50-59

Helm S (1970) Prevalence of malocclusion in relation to development of the dentition. An epidemiological study of Danish school children. Acta Odontol Scand 58: 122-128

Hopcraft M, Morgan M (2003) Dental caries experience in a young adult military population. Aust Dent J 48: 125-129

Hoskins WE, Asling CW (1977) Influence of growth hormone and thyroxine on endochondral osteogenesis in the mandibular condyle and proximal tibial epiphysis. J Dent Res 56: 509-517

Howe RP, McNamara JA, O'Connor KA (1983) An examination of dental crowding and its relationship to tooth size and arch dimension. Am J Orthod 83: 363-373

Hunter WS, Smith BRW (1972) Development of mandibular spacing-crowding from 9 to 16 years of age. J Can Dent Assoc 38: 178-185

Karlsen AT (1995) Craniofacial growth differences between low and high MP-SN angle males: a longitudinal study. Angle Orthod 65: 341-350

Kjellberg H, Beiring M, Albertsson Wikland K (2000)
Craniofacial morphology, dental occlusion, tooth eruption, and dental maturity in boys of short stature with or without growth hormone deficiency. Eur J Oral Sci 108: 359-367

Leighton BC, Hunter WS (1982) Relationship between lower arch spacing/crowding and facial height and depth. Am J Orthod 82: 418-425

Lewis AB (1991) Comparisons between dental and skeletal ages. Angle Orthodontist 61: 87-92

Lundstrom A (1951) The aetiology of crowding of the teeth and its bearing on orthodontic treatment. Trans Eur Orthod Soc 87: 176-191

Lundstrom A (1975) A study of the correlation between mandibular growth direction and changes in incisor inclination, overjet, overbite and crowding. Trans Eur Orthod Soc : 131-140

Melo L, Ono Y, Takagi Y (2001) Indicators of mandibular dental crowding in the mixed dentition. Pediatr Dent 23: 118-122

Miethke RR, Behm-Menthel A (1988) Correlations between lower incisor crowding and lower incisor position and lateral craniofacial morphology. Am J Orthod Dentofacial Orthop 94: 231-239

Morarasu C, Burlui V, Zbranca E (1997) Cephalometric changes in acromegaly. Rev Med Chir Soc Med Nat Iasi 101: $120-124$

Moskers O, Aubry M, Mafart B (2004) Dental crowding in a prehistoric population. Eur J Orthod 26: 151-156

Nanda SK (1988) Patterns of vertical growth in the face. Am J Orthod Dentofacial Orthop 93: 103-116

Nanda SK (1990) Growth patterns in subjects with long and short faces. Am J Orthod Dentofacial Orthop 98: 247-258

Otuyemi OD, Ogunyinka A, Dosumu O, Cons NC, Jenny J (1999) Malocclusion and orthodontic treatment need of secondary school students in Nigeria according to the dental aesthetic index (DAI). Int Dent J 49: 203-210

Perera PSG (1987) Rotational growth and incisor compensation. Angle Orthod 57: 39-49

Proffit WR, Fields HW Jr, Moray LJ (1998) Prevalence of malocclusion and orthodontic treatment need in the United States: estimates from the NHANES III survey. Int J Adult Orthodon Orthognath Surg 13: 97-106

Richardson PS, McIntyre IG (1996) Dental treatment needs of a cohort of Royal Air Force recruits over 5 years. Community Dent Health 13: 11-16

Ronnerman A, Thilander B (1978) Facial and dental arch morphology in children with and without early loss of deciduous molars. Am J Orthod 73: 47-58

Sakuda M, Kuroda Y, Wada K, Matsumoto M (1976) Changes in crowding of teeth during adolescence and their relation to the growth of the facial skeleton. Trans Eur Orthod Soc 1976: 93-104

Sampson WJ, Richards LC (1985) Prediction of mandibular incisor and canine crowding changes in the mixed dentition. Am J Orthod 88: 47-63

Sanin C, Savara BS (1973) Factors that affect the alignment of 
the mandibular incisors: a longitudinal study. Am J Orthod 64: 248-257

Sarnat H, Kaplan I, Pertzelan A, Laron Z (1988) Comparison of dental findings in patients with isolated growth hormone deficiency treated with human growth hormone (hGH) and in untreated patients with Laron-type dwarfism. Oral Surg Oral Med Oral Pathol 66: 581-586

Schudy FF (1965) The rotation of the mandible resulting from growth: its implications in orthodontic treatment. Angle Orthod 35: 36-50

Sgan-Cohen HD, Katz J, Horev T, Dinte A, Eldad A (2000) Trends in caries and associated variables among young Israeli adults over 5 decades. Community Dent Oral Epidemiol 28: 234-240

Sinclair PM, Little RM (1983) Maturation of untreated normal occlusions. Am J Orthod 83: 114-123

Siriwat PP, Jarabak JR (1985) Malocclusion and facial morphology: is there a relationship? An epidemiologic study. Angle Orthod 55: 127-138

Tanabe Y, Taguchi Y, Noda T (2002) Relationship between cranial base structure and maxillofacial components in children aged 3-5 years. Eur J Orthod 24: 175-181

Tang ELK (1994) The prevalence of malocclusion amongst Hong Kong male dental students. Br J Orthod 21: 57-63

Tanner JM (1962) Growth at Adolescence. 2nd ed. Basil Blackwell, Oxford

Tata JR (1976) Growth-promoting actions of peptide hormones. Ciba Found Symp 41: 297-312

Thilander B (1995) Basic mechanisms in craniofacial growth. Acta Odontol Scand 53: 144-151

Thilander B, Pena L, Infante C, Parada SS, Mayorga C (2001) Prevalence of malocclusion and orthodontic treatment need in children and adolescents in Bogotá, Colombia. An epidemiological study related to different stages of dental development. Eur J Orthod 23: 153-167
Van Erum R, Carels C, Verbeke G, de Zegher F (1997) Craniofacial growth in short children born small for gestational age: two years follow-up after high-dose growth hormone treatment. J Craniofac Genet Dev Biol 17: 184-189

Van Erum R, Mulier G, Carels C, de Zegher F (1998a) Craniofacial growth and dental maturation in short children born small for gestational age: effect of growth hormone treatment. Own observations and review of the literature. Horm Res 50: 141-146

Van Erum R, Mulier M, Carels C, de Zeghe F (1998b) Short stature of prenatal origin: craniofacial growth and dental maturation. Eur J Orthod 20: 417-425

Vandeberg JR, Buschang PH, Hinton RJ (2004) Craniofacial growth in growth hormone-deficient rats. Anat Rec A Discov Mol Cell Evol Biol Jun 278: 561-570

Vyslozil O, Jonke E (1994) Kieferorthopädischantropometrische Vergleichsuntersuchungen 100 Jahre alten menschlichen Schädeln und österreichischen Bundesheersoldaten. IOK 26: 409-436

Zachmann M (1992) Interrelations between growth hormone and sex hormones: physiology and therapeutic consequences. Horm Res 38: 1-8

This article was presented at the 8th International Congress of Physiological Anthropology, 2006 (ICPA 2006), in Kamakura, Japan.

Received: September 30, 2006

Accepted: March 6, 2007

Correspondence to: Nadezda V. Lupacheva, 35127, Via Vecchia 14, Padova, Italy

Phone: +39-333-888-1148

e-mail: nadezda@nm.ru lupacheva@list.ru 